\title{
Análise etnográfica das relações de gênero em brincadeiras realizadas por um grupo de crianças de pré-escola: contribuições para uma pesquisa em busca dos significados ${ }^{1}$
}

Alan Marques da Silva* Jocimar Daolio **

\begin{abstract}
Resumo: Esta pesquisa partiu do referencial fornecido pelas Ciências Humanas, em especial o da Antropologia Social, para analisar como um determinado grupo de crianças de pré-escola confere significados às relações de gênero nas brincadeiras por elas realizadas no ambiente de uma creche. Neste trabalho foi enfatizado o procedimento teóricometodológico utilizado para a realização da pesquisa, por possibilitar a interpretação do enredo composto pelas categorias de infância, gênero e instituição escolar. Além disso, a pesquisa qualitativa tem se tornado freqüente na área de Educação Física, ampliando a compreensão dos significados presentes nas ações humanas.
\end{abstract}

Palavras-chave: Antropologia cultural. Identidade de gênero. Pré-escolar.

\section{INTRODUÇÃO}

$\mathrm{Na}$ área de Educação Física, a pesquisa qualitativa ainda é recente, porém promissora. Nos últimos anos, várias pesquisas têm sido desenvolvidas a partir de referenciais oriundos das Ciências Humanas, o que tem renovado a compreensão sobre os fenômenos tradicionais da área. Um exemplo disso é a publicação A Pesquisa Qualitativa na Educação Física, de Molina Neto e Triviños, de

\footnotetext{
${ }^{1}$ Artigo resultante do trabalho de conclusão de curso defendido na Faculdade de Educação Física da Unicamp em 2003, sob orientação do Prof. Dr. Jocimar Daolio, com o título de Infância, Jogo e Gênero: uma etnografia do brincar.

* Licenciado em Educação Física. Professor da rede pública de ensino em Campinas-SP. Membro do Grupo de Estudo e Pesquisa Educação Física e Cultura (GEPEFIC). E-mail alamsfef@yahoo.com

**:Docente da Faculdade de Educação Física da Unicamp. Coordenador do Grupo de Estudo e Pesquisa Educação Física e Cultura (GEPEFIC). E-mail: jocimar@fef.unicamp.br
} 
1999. Espera-se, dessa forma, que a área acadêmica da Educação Física possa realizar mais trabalhos voltados para o âmbito local e microscópico, considerando as manifestações e ressignificações expressas e constantemente atualizadas pelos sujeitos na dinâmica dos jogos, esportes, brincadeiras, danças, formas de ginástica e outros elementos tradicionais que compõem a área.

O estudo da infância pelo viés das Ciências Humanas resultou em inúmeros trabalhos nas mais diversas áreas de pesquisa: história, sociologia, antropologia, pedagogia. Chegou-se até mesmo a constituir um campo específico para estudo dessa categoria dentro da Sociologia, a denominada Sociologia da Infância. Essa área de conhecimento foi se configurando a partir de uma visão que considera a criança como um grupo social específico, com características próprias, quebrando uma tradição teórica que considerava tal grupo como um simples objeto passivo (SIROTA, 2001). Assim, James e Prout (apud SIROTA, 2001, p.18), ao caracterizarem a infância como uma construção social, apontam que:

\begin{abstract}
A infância é compreendida como uma construção social. Desse modo, ela fornece um quadro interpretativo que permite contextualizar os primeiros anos da vida humana. A infância, vista como fenômeno diferente da imaturidade biológica, não é mais um elemento natural ou universal dos grupos humanos, mas aparece como um componente específico tanto estrutural quanto cultural de um grande número de sociedades.
\end{abstract}

Na área acadêmica da Antropologia Social, Tedrus (1998) afirma que nas escolas tradicionais da área (escolas inglesa, francesa e norte-americana) e na própria tradição brasileira são poucos os estudos realizados tendo por base a criança como sujeito social. O que a autora encontrou em sua pesquisa foram estudos que centram sua análise nos processos de socialização da criança, fenômeno este presente em todas sociedades de acordo com a organização social característica de cada uma dessas.

Nos trabalhos analisados, centrados em sociedades indígenas/ rurais e em sociedades urbano-industriais, a autora verifica que,

Movimento, Porto Alegre, v.13, n. 01, p.13-37, janeiro/abril de 2007. 
nos primeiros grupos, a socialização da criança tem por base o grupo familiar, que, nesse caso, encontra-se entrelaçado com a unidade de produção, fazendo com que a socialização da criança ocorra num movimento de incorporação ao mundo do trabalho e dos valores dos adultos. No segundo grupo, o das sociedades urbanoindustriais, o processo de produção da individualidade dificulta a entrada do individuo no âmbito do trabalho, a socialização ultrapassa a esfera do grupo familiar e atinge os níveis de uma socialização do tipo institucional. Nesse sentido, “[...] a escola é percebida como uma lenta preparação para a vida, ao contrário do que se verifica no caso da educação rural" (BRANDÃO, 1983, p.245 apud TEDRUS, 1998, p.23). ${ }^{2}$ Percebe-se claramente que se nesse tipo de sociedade a escola é compreendida como uma forma de preparação (para a vida, para o mercado de trabalho, para o consumo), concebendo a criança como devir.

Na concepção da autora, e do próprio pensar antropológico, a categoria criança está ligada a determinadas representações sociais, ou seja:

\begin{abstract}
'Ser criança', como uma categoria construída, implica o indivíduo estar incluído não somente em uma fase etária, de zero a 12 anos, digamos, mas partilhar de um modo de ser, de agir, de existir, de sentir, de falar, ou ainda, de um 'estado de espírito' que são históricos e culturais (TEDRUS, 1998, p.38)
\end{abstract}

Oliveira (2005), ao analisar o conceito de infância nos trabalhos acadêmicos da área da Educação Física no período compreendido entre 1980 e 2002, verifica que grande parte dos trabalhos lida com a idéia de infância ainda de forma idealizada. Isso ocorre, segundo a autora, por dois principais motivos: a própria forma idealizada com a qual a sociedade aborda a questão da infância e os condicionantes históricos da própria área de Educação Física. Porém, a autora também verifica que os trabalhos da área, a partir

${ }^{2} \mathrm{O}$ que se verifica na análise da autora é que nas sociedades urbano-industriais o acesso à escola não ocorre de forma igual.

Movimento, Porto Alegre, v.13, n. 01, p.13-37, janeiro/abril de 2007. 
da década de 1990, já procuraram repensar o conceito de infância ao considerar a criança como sujeito histórico-cultural.

A temática do gênero também é abordada pelas pesquisas em Ciências Humanas nas mais diversas áreas, tais como a História, a Sociologia, a Antropologia e também na própria Educação Física. ${ }^{3}$ Em relação ao gênero, é importante distinguirmos num primeiro momento a palavra "sexo" da palavra "gênero". Sara Delamont (1985) afirma que a palavra "sexo" diz respeito aos aspectos biológicos que distinguem machos e fêmeas; já a palavra "gênero" é utilizada para acentuar as diferenças não biológicas existentes entre os sexos, tais como os comportamentos, os interesses, os vestuários etc.

É nesse contexto que Louro (1999, p.11) afirma que "A inscrição dos gêneros - feminino e masculino - nos corpos é feita, sempre, no contexto de uma determinada cultura e, portanto, com as marcas dessa cultura". Nas palavras de Rosaldo (1980, apud SCOTT, 1990, p.86) "[...] devemos buscar não uma causalidade geral e universal, mas uma explicação baseada no significado[...]". Ou seja, para além de concepções generalizantes e universais em relação ao ser 'homem' e ao ser 'mulher', cada cultura constrói um conjunto de significados em torno dessas categorias que varia historicamente e se liga a um determinado contexto social específico.

Um estudo clássico existente dessa relação entre as questões de gênero e a escola, entendida como local privilegiado de socialização das crianças, foi desenvolvido por Sara Delamont (1985) em sua obra denominada Os papéis sexuais e a escola. Nesta obra, a autora apresenta inúmeros exemplos de como o cotidiano escolar está impregnado de idéias estereotipadas sobre as funções masculinas e femininas, desenvolvendo um interessante estudo no qual coloca a escola como a instituição da sociedade que mais fortalece as diferenças de gênero ao realizar processos de socialização diferenciados para meninos e meninas.

${ }^{3} \mathrm{Na}$ Educação Física, em específico um trabalho publicado por Luz Júnior (2003), Educação Física e Gênero: olhares em cena, apresenta importante contribuição para a análise dos trabalhos produzidos na pós-graduação strictu senso da área de Educação Física.

Movimento, Porto Alegre, v.13, n. 01, p.13-37, janeiro/abril de 2007. 
Ainda nesse âmbito de análise, Louro (1995) afirma que a construção do gênero caracteriza-se por um processo pelo qual toda a sociedade está envolvida, a partir de suas diferentes instituições, seus discursos, práticas e simbolismos. A autora também aponta que a construção de homens e mulheres dá-se num processo de relação, cujos sujeitos são distintos historicamente. Dessa forma, homens e mulheres sempre foram e serão diferentes, pois há diferenças entre culturas, e essas diferenças também se encontram entre os grupos situados em determinada cultura. O problema é quando se procura atribuir tais diferenças a uma ordem "natural" na qual transforma-se, por um lento e gradativo processo que pertence à esfera cultural, as diferenças em desigualdades.

Louro (1995, p.3) aponta que:

[...] acabamos por naturalizar o que é social, acabamos por 'colar', aos corpos femininos e masculinos, destinos, possibilidades, sentimentos, disposições, tornando-os 'inerentes' a cada um dos gêneros. Atributos que são sociais e históricos - portanto atributos que são produzidos e fabricados de diferentes modos, por diferentes sujeitos, em diferentes momentos e sociedades - acabam por serem percebidos como universais e eternos.

Porém, é importante ressaltar que a autora, ao defender a idéia da escola como uma das instituições "produtora" de sujeitos, constata que não se participa passivamente nesse processo, ou seja somos fabricados e nos fabricamos durante o processo de escolarização. Dessa forma, as crianças analisadas também participam desse processo como atores na construção de seus próprios corpos. Se pensarmos na infância e na sua relação com o ambiente escolar, podemos considerar que a criança, nesse caso representando o papel de aluno, não constrói sua identidade de gênero somente pela ação direta que sofre na família ou na escola.

\section{O CONCEITO DE CULTURA E A ANÁLISE ETNOGRÁFICA}

Quando abordamos a questão da infância e do gênero num contexto de construção cultural, faz-se necessário, num primeiro

Movimento, Porto Alegre, v.13, n. 01, p.13-37, janeiro/abril de 2007. 
momento, discutir o conceito de cultura, um conceito-chave na área de conhecimento da Antropologia Social. O conceito de cultura na Antropologia foi se modificando ao longo do tempo, assim como a própria configuração dessa área de conhecimento. No século XIX, a Antropologia ainda se configurava numa estreita ligação com a concepção evolucionista de ser humano. O conceito de cultura que permeava a área nessa época remetia a um conjunto de produções materiais de determinado grupo social. Esse mesmo conceito foi utilizado para estabelecer comparações entre esses diversos grupos, colocando seres humanos com culturas diferentes como inferiores e fortalecendo uma visão preconceituosa que justificou por muito tempo a intervenção das culturas ditas "civilizadas" nas chamadas culturas "primitivas".

Clifford Geertz (1989), tendo por base a Semiótica, procurou desenvolver um conceito de cultura mais específico para a área, considerando-a como um sistema simbólico que orienta e dá sentido à existência humana. Assim, o entendimento do conceito de cultura será aqui compreendido a partir da definição de Geertz (1989, p.15) ao colocar que: "Acreditando, como Max Weber, que o homem é um animal amarrado a teias de significados que ele mesmo teceu, assumo a cultura como sendo essas teias e a sua análise". Nessa concepção, o ser humano é visto como um animal que utiliza símbolos, e o que define o homem é sua capacidade de exibir um comportamento simbólico. Chauí (1994, p.294), ao ressaltar a especificidade do estudo da Antropologia no sentido de atribuir à cultura uma ordem simbólica, afirma que

Quando dizemos que a Cultura é a invenção de uma ordem simbólica, estamos dizendo que nela e por ela os humanos atribuem à realidade significações novas por meio das quais são capazes de se relacionar com o ausente.

Se a constituição da Antropologia foi permeada por inúmeras mudanças de concepções, isso também ocorreu em seus métodos de análise. A etnografia, um dos principais instrumentos de análise utilizados pelos antropólogos, foi se modificando, assim como a própria Antropologia.

Mavimento, Porto Alegre, v.13, n. 01, p.13-37, janeiro/abril de 2007. 
Já no final do século XIX e início do século XX, alguns pesquisadores(as), a partir dos estudos provenientes de suas práticas de campo com nativos, procuraram compreender os comportamentos desses grupos pela lógica de significados que os orientava Esse foi o principal ponto de transformação dos conceitos de ser humano e cultura na Antropologia, que, a partir desse momento, passou a ser a ciência que procurava compreender os seres humanos em suas particularidades culturais. Essas transformações possibilitaram que os seres humanos fossem vistos como culturalmente diferentes e a cultura considerada como um processo dinâmico inerente a todos os humanos.

Nesse período, alguns autores se destacaram nessa nova configuração da Antropologia e, conseqüentemente, da etnografia. Laplantine (1988) ressalta os estudos de Boas (1858-1942) e Malinowski (1884-1942). Este último destacou-se principalmente por revolucionar a prática etnográfica ao entrar diretamente em contato com as populações que estudava, rompendo com a tradição dos viajantes ou missionários. ${ }^{4}$ No livro Os Argonautas do Pacífico Ocidental, ao estudar os valores e costumes dos trobriandeses, Malinowski afirmava que os mesmos possuíam uma lógica e uma coerência em suas ações e comportamentos, não sendo apenas ações dotadas de misticismo pertencente a um povo primitivo e "culturalmente" atrasado.

Para Laplantine (1988), a etnografia configura-se como uma experiência de "imersão total" que, longe de executar uma análise "de fora", "de longe", "em suas manifestações exteriores", compreende a sociedade (ou grupo estudado) nas significações que os próprios sujeitos atribuem a seus comportamentos, caracterizando o movimento "de dentro", "do próximo". Nesse caso, é importante considerarmos o fato de que, quem olha um determinado fenômeno,

${ }^{4}$ As observações anteriores a esse período eram realizadas por viajantes ou missionários, que as enviavam para os pesquisadores que as analisavam em seus gabinetes. Porém, a etnografia só veio adquirir o importante papel que possui a partir do momento em que se percebe, segundo Laplantine (1988, p.75), que "[...] o pesquisador deve ele mesmo efetuar no campo sua própria pesquisa, e que esse trabalho de observação direta é parte integrante da pesquisa".

Movimento, Porto Alegre, v.13, n. 01, p.13-37, janeiro/abril de 2007 
observa-o com o viés de sua cultura, com uma determinada lógica de significados, o que, de certa forma, influencia a análise.

O autor aponta que um primeiro momento de análise caracteriza-se por essa "imersão", essa "impregnação" pelos hábitos e comportamentos nessa determinada sociedade (ou grupo), atentando, num segundo momento, para uma "separação", na qual o observador, ao olhar "de fora", adequa o que foi visto a uma linguagem científica, num movimento que procura compreender aquilo que foge da lógica dos atores sociais. E é nesse movimento que se constitui a análise etnográfica. Movimento próprio da observação participante, situado na tênue fronteira que separa essas duas realidades distintas. Para o autor, procura-se analisar a "rede densa das interações" que caracteriza o grupo social.

Colocadas algumas questões históricas acerca do conceito de cultura e da análise etnográfica, desenvolvemos nessa pesquisa uma abordagem etnográfica que fosse capaz de permear a lógica de significados de um determinado grupo social, baseando-se e aproximando-se daquilo que Geertz (1989) denomina de "descrição densa". Este autor, ao caracterizar a etnografia como uma descrição densa, aponta que o etnógrafo, ou pesquisador, deparase com uma:

[...] multiplicidade de estruturas conceptuais complexas, muitas delas sobrepostas ou amarradas umas às outras, que são simultaneamente estranhas, irregulares e inexplícitas, e que ele tem que, de alguma forma, primeiro apreender e depois apresentar (GEERTZ, 1989, p.20)

Para o autor, a Antropologia seria compreendida como uma ciência interpretativa em busca dos significados. A visão semiótica trazida por Geertz $(1989$, p.35) à Antropologia tem como ponto chave "[...] auxiliar-nos a ganhar acesso ao mundo conceptual no qual vivem os nossos sujeitos, de forma a podermos, num sentido um tanto mais amplo, conversar com eles".

O estudo clássico de Geertz mostrou como um jogo, aparentemente simples, a briga de galos em Bali, quando estudada como

Movimento, Porto Alegre, v.13, n. 01, p.13-37, janeiro/abril de 2007. 
um "jogo profundo e absorvente" para seus praticantes, pode revelar toda uma gama de significados presentes em um determinado grupo social. Nesse sentido, a briga de galos é compreendida como um 'texto', como a 'inscrição da ação'.

Essa concepção da cultura como texto foi desenvolvida por Geertz numa determinada fase de sua carreira acadêmica, na qual começa a sofrer influência de vários autores, entre eles a do filósofo francês Paul Ricoeur. Foi a partir daí que sua obra avançou no domínio do simbolismo, do significado e da hermenêutica. ${ }^{5}$ Para Kupper (2002, p.141) "[...] o que Geertz extraiu de Ricoeur foi a idéia de que como as ações humanas transmitem significados, elas podiam (e deviam) ser lidas de forma bastante semelhante aos textos escritos". Logo, “[...] se a cultura representa um sistema simbólico, os processos culturais devem ser lidos, traduzidos e interpretados" (KUPPER, 2002, p.132).

A idéia de Ricoeur apontada por Kupper era a de que as Ciências Humanas serão consideradas hermenêuticas quando o seu objeto for tratado como texto e a metodologia desenvolver procedimentos de interpretação desse texto.

Segundo Geertz, o que o antropólogo realiza é, na verdade, a leitura de um texto sobre os ombros dos seus informantes, levando o mesmo a construir um texto próprio. Para o autor, o etnógrafo anota o discurso social e fixa, pela escrita, o significado dos acontecimentos. As características da descrição etnográfica seriam, então, o seu caráter interpretativo, no sentido de interpretar o fluxo do discurso social e fixar o 'dito' em formas pesquisáveis, além de seu caráter microscópico. O que se anota, na verdade, é o significado que as ações sociais particulares têm para os atores em questão, numa análise que recai sobre a mensagem que o determinado fenômeno cultural transmite.

${ }^{5}$ Para Oliveira (1997), o paradigma hermenêutico na antropologia buscava a negação de um discurso cientificista e a reformulação de elementos até então domesticados pela mesma (a individualidade, a historicidade e a subjetividade) por provocarem desordem na mesma.

Movimento, Porto Alegre, v.13, n. 01, p.13-37, janeiro/abril de 2007. 


\section{A PESQUISA DE CAMPO}

A observação do grupo de crianças em questão baseou-se na análise etnográfica, caracterizada, segundo André (1995, p.27), por “[...] (1) um conjunto de técnicas para coletar dados sobre os valores, os hábitos, as crenças, as práticas e os comportamentos de um grupo social e (2) um relato escrito resultante do emprego dessas técnicas". Para a autora, o estudo etnográfico caracteriza-se pela busca de formulação de hipóteses, conceitos, novas formas de entendimento da realidade. O que se propõe é uma interpretação de uma determinada realidade, não o seu retrato ou sua reprodução. É importante a consideração da autora ao apontar que o pesquisador oferece apenas uma representação/reconstrução do real, admitindo a possibilidade da existência de outras.

Na concepção de Celso Azzan Jr. (1993, p.99):

Como texto, a cultura é um mundo constituído de significados produzidos e interpretados, especialmente um mundo que abre a possibilidade de significados novos segundo interpretações novas, inseridas em situações novas, envolvendo novos interesses, sempre no sentido de refazer as leituras possíveis segundo a tradição na qual estão inseridos o texto e o leitor.

A presente pesquisa, portanto, foi construída no intuito de compreendermos como texto a inter-relação entre as categorias de gênero e infância articuladas nas brincadeiras de um grupo de crianças da pré-escola. Amparada pelo referencial das Ciências Humanas, a pesquisa etnográfica se desenvolveu em uma Escola Municipal de Educação Infantil (EMEI) situada na cidade de Campinas, SP. A análise centrou-se em uma das seis turmas da escola,${ }^{6}$ cuja faixa etária estava compreendida entre seis e sete anos, na qual observamos as relações estabelecidas entre os membros dessa turma e com as outras turmas que compartilhavam o mesmo

${ }^{6}$ As seis turmas da escola dividiam-se em duas turmas com idades entre quatro e cinco anos, duas turmas com idade entre cinco e seis anos e duas turmas com idade entre seis e sete anos.

Mavimento, Porto Alegre, v.13, n. 01, p.13-37, janeiro/abril de 2007. 
horário e espaço do parque (o que denominaremos de 'horário do parque'), realizando ali suas brincadeiras. Esse horário (com duração de cinqüenta minutos, aproximadamente) era um dentre outros: o horário das atividades em sala de aula, o horário do lanche, horário da piscina, biblioteca etc.

Foram realizadas vinte e três sessões de observação numa frequiência de três vezes por semana. Durante o horário do parque, o desenrolar das brincadeiras era anotado em um 'diário de campo', no qual se registravam as observações relativas às dinâmicas das brincadeiras, aos diálogos entre as próprias crianças, às intervenções da professora, à ocupação dos diferentes espaços da escola pelas crianças e, principalmente, aos diálogos travados na interação entre as crianças e o pesquisador, algo muito presente nesse tipo de pesquisa. Enfim, analisamos a complexidade presente na organização e realização das brincadeiras em relação à concepção de infância e gênero no ambiente escolar, tendo por fim a tentativa de interpretar alguns de seus significados.

Uma das atividades mais observadas durante o horário do parque na turma em questão foi o jogo de futebol. O futebol foi jogado praticamente todos os dias de observação, sendo uma das atividades percebidas desde os primeiros dias. Era praticado por todas as turmas e idades, porém, dificilmente com mistura de alunos de salas diferentes e era, principalmente, jogado pelos meninos. Foi dessa forma que percebemos a forte rivalidade existente entre as turmas, que se construía pela mistura dos códigos criados por cada grupo específico. A presença de uma criança de outra turma era denunciada pelas próprias crianças à professora. Por isso o futebol geralmente era jogado somente entre os membros da mesma sala, apenas um ou outro de uma sala juntava-se ao grupo, submetendo-se, dessa forma, às regras criadas por esse grupo.

O jogo de futebol possuía uma vivacidade a cada movimento realizado por seus praticantes na disputa de cada jogada, de cada lance. Um aspecto que chamava a atenção de um observador atento era o extremo uso da força física que faziam os meninos que participavam do jogo de futebol. Era uma mistura de empurrões, carrinhos,

Movimento, Porto Alegre, v.13, n. 01, p.13-37, janeiro/abril de 2007. 
pernadas, chutes, lances de segurar a camiseta. Numa das observações, foram comuns os gritos de "Tem que quebrar!", "Quebra ele!”. Geralmente, aqueles que sofriam as agressões reclamavam, porém isso não impedia que também agissem de forma mais violenta nos lances posteriores ou em outros jogos.

Quando algum menino reclamava à sua professora sobre algum tipo de 'agressão' sofrida no jogo, geralmente ouvia na mais profunda calma de sua professora: "O jogo é assim mesmo, a gente corre, cai". Outros meninos que ficavam em volta concordavam com a fala da professora: "É assim mesmo!". Muitas vezes, essa cena de dirigir-se à professora para reclamar de uma "agressão" sofrida foi presenciada. Quando a professora, algumas vezes, resolvia "advertir" o "agressor", realizava mais para "acalmá-lo" do que realmente para adverti-lo. Certa vez, um menino se dirigiu à professora e avisou que dois meninos estavam brigando. A professora mandou chamar os dois e perguntou o que havia acontecido. O menino, que estava quase chorando, disse que o outro "bateu" nele. O "agressor", por sua vez, interrompeu a fala do "agredido" e disse com muita convicção que não bateu nele, não deu soco, apenas uma rasteira, um carrinho do futebol. A professora procurou então acalmar o 'agredido' e mais uma vez colocar isso como uma característica do jogo.

Foi interessante também observarmos as tentativas das meninas em participarem do jogo de futebol. Num determinado momento, uma menina entrou no jogo, mas saiu poucos minutos depois. Logo em seguida, uma outra menina entrou no jogo, porém, nas poucas vezes em que teve a oportunidade de tocar a bola, foi muito cobrada pelos meninos que estavam jogando, muitas vezes até com palavras ofensivas. Assim, sua permanência naquele jogo teve vida curta. O que se demonstrava dava a impressão de ser uma tentativa de tirar de qualquer forma aquela "intrusa" do jogo.

A própria professora da turma também desfrutou por pouco tempo desse jogo quando resolveu brincar com os meninos. Entretanto, não verificamos, por parte dos meninos, uma atitude mais agressiva em relação a ela. A bola era chutada de um lado para o

Movimento, Porto Alegre, v.13, n. 01, p.13-37, janeiro/abril de 2007. 
outro com bastante força, mas o contato corporal e a dinâmica (ritmo) do jogo diminuíram. Quando a professora retirou-se, juntouse a um grupo de meninas e começou a jogar futebol com elas. Quando ela parou de jogar, as meninas logo desistiram e foram realizar outra atividade no parque. Nesse deslocamento de olhar, decorreu o tempo necessário para que o jogo de futebol dos meninos retomasse sua dinâmica característica.

Ao retomar essa dinâmica, foi observada uma cena muito interessante sobre os significados do jogo de futebol para os meninos. Num determinado momento, um menino reclamou que não queria mais a presença de outro, alegando que o mesmo ficava puxando sua camiseta durante todo o jogo. Então, ele parou o jogo, segurou a bola e começou a discursar, alegando que o menino deveria ser expulso do jogo. Os outros meninos tentavam tirar a bola de sua mão para continuar o jogo, porém sem êxito, já que o menino estava disposto a interromper a partida enquanto o possível "transgressor" não fosse retirado. Após alguns minutos de discussão, um outro menino resolveu tomar uma atitude: "partiu para cima" do denunciante, peitando-o, e dizendo que o possível "transgressor" não iria sair do jogo, afrontando diretamente suas ordens. A partir daí, seguiu-se uma seqüência de "peitadas" e acusações; outros meninos se juntaram à discussão, formando-se um grande grupo que diziam palavras tais como "vai, o que é que é?", "yeah!”. Era uma grande confusão regada a gritos, "peitadas", empurrões etc. Aparentemente, isso se caracterizaria numa daquelas discussões nas quais seria necessária uma intervenção. Aparentemente, se tudo não se tratasse de uma "simulação". Passados alguns minutos, bastou um dos meninos rir para que todos começassem a rir e a se empurrar, logo recomeçando o futebol novamente.

Em certo momento durante o jogo de futebol, após um chute forte sem direção de um menino, a bola foi para um palco do anfiteatro da escola, situado ao lado do espaço que os meninos utilizavam para o jogo de futebol, sendo avidamente seguida pelos meninos. Uma menina que presenciou a cena naquele momento gritou num tom de irritação: "Ei, o palco é para dançar, para o balé... não é

Movimento, Porto Alegre, v.13, n. 01, p.13-37, janeiro/abril de 2007. 
para jogar!”. A bola já há muito havia saído do palco devido à dinâmica do jogo, porém isso foi algo que chamou a atenção.

Dentre as atividades presenciadas naquele palco durante as observações, foi observada a execução de uma coreografia pelas meninas de uma música muito veiculada nos meios de comunicação de massa naquele período. Ao perguntar às crianças sobre as atividades ali desenvolvidas, elas respondiam que o palco era principalmente utilizado durante o ano letivo para a realização de coreografias para festividades da escola.

Quando os meninos ficavam observando a dança das meninas, muitas vezes eram instigados pela professora para que também se juntassem a elas no palco. Muitos até concordavam, porém, num rápido e súbito movimento, desviavam de rumo e começavam a correr atrás da bola de futebol com os outros meninos. Foi então que começaram os questionamentos sobre os códigos ali criados que inibiam os meninos de dançarem no palco com as meninas. Algumas vezes, um grupo de meninos ocupava o espaço do palco e realizava determinados movimentos característicos do balé. Eles rodopiavam, um de cada vez, e colocavam a mão acima da cabeça. O que mais chamou a atenção nesta atividade foi o fato dos meninos rirem muito durante a execução dos gestos, muitas vezes realizandoos de forma "desengonçada", num tom de escárnio.

Outra atividade muito presenciada durante as observações foi a brincadeira da casinha. A maioria das crianças que brincava de casinha era composta por meninas, porém isso não impedia que os meninos também brincassem algumas vezes, porém de forma isolada, já que a relação entre meninos e meninas era dificultada. A presença dos meninos nas brincadeiras de casinha era algo extremamente perturbador para as meninas, que geralmente reclamavam com a professora. Essa relação entre meninos e meninas na casinha se desenrolava de forma um pouco agressiva, pois as meninas alteravam o tom de voz, colocavam-se mais próximas aos brinquedos da "casinha" e se posicionavam de costas para os meninos.

Nas poucas vezes em que presenciamos meninos na tentativa de se juntarem às meninas para brincarem, logo esses eram Movimento, Porto Alegre, v.13, n. 01, p.13-37, janeiro/abril de 2007. 
denunciados pelas meninas para a professora, ou que estavam incomodando ou que não as deixavam brincar. Aparentemente, a única coisa que os meninos queriam era a chance de brincarem junto com elas, porém qualquer tentativa de algum menino brincar de casinha não era bem recebida pelas meninas. Quando um dos meninos da turma começou a se interessar pela brincadeira da casinha, acabou ficando "deslocado", não conseguindo interagir com as meninas. Esse menino logo foi embora, mas depois retornou liderando um grupo de meninos que começou a jogar gravetos na casinha das meninas.

Os meninos que se dispunham a brincar com as meninas tinham que se sujeitar às regras criadas pelas próprias meninas, não podendo exprimir nenhum tipo de comentário ou sugestão para modificar a estrutura da "casa", apenas contentavam-se em apreciar os objetos da "casa", tocá-los por algumas vezes, mas sem se atrever a mudá-los de lugar. Quando isso ocorria, os meninos eram duramente repreendidos por qualquer menina que estivesse mais próxima do local e, em último caso, sua presença na brincadeira diretamente era denunciada à professora, que pedia para que o mesmo se retirasse do local. ${ }^{7}$

A formação dos grupos era de fundamental importância para direcionar grande parte dos comportamentos dos indivíduos. Os grupos formados pelos meninos movimentavam-se muitas e muitas vezes de um brinquedo para outro no espaço do parque. Durante esses deslocamentos, a atividade mais observada foi a brincadeira por eles denominada de "lutinha". A "lutinha" caracterizava-se por uma sequiência de golpes (socos e chutes), empurrões e movimentos de agarrar o oponente, podendo se desenvolver em qualquer espaço do parque. Algumas vezes foi possível observar um grupo de meninas realizando uma brincadeira parecida com a "lutinha".

Certa vez, um menino tentou pegar o carrinho de supermercado da casinha e foi denunciado por uma menina que disse à professora: "Tia, ele está levando as coisas pra lá". A professora logo repreendeu o menino ("P., deixa as coisas aí e vai brincar com os meninos") que, dessa forma, despejou os acessórios no chão, ainda ficando ali por perto. Depois foi brincar com os meninos de uma outra turma e voltou mais tarde a brincar de casinha, mas agora sozinho.

Movimento, Porto Alegre, v.13, n. 01, p.13-37, janeiro/abril de 2007. 
Elas se davam socos e chutes de forma um pouco mais lenta, paradas no local, muitas vezes nem acertando a "adversária". O que nos chamou a atenção foi o fato delas também rirem bastante durante a execução desses gestos, realizando-os com escárnio, assim como os meninos quando executavam os gestos do balé no palco.

Certa vez, um grande grupo de meninos com integrantes das mais diversas salas, na maioria da pré-escola, estavam num determinado brinquedo do parque e notamos apenas a presença de uma menina junto àquele imenso grupo. De repente, esse grande grupo de meninos começou a correr atrás da menina, provocando-a. Durante o trajeto da perseguição, outras meninas que viram a cena diziam: "Meninos da nossa sala são fogo!". O grupo continuou a perseguição até que a menina chegou à sua professora e falou alguma coisa. Os meninos cessaram a "caçada" momentaneamente, ficando ainda por perto da menina. Quando a menina saiu do lado da professora, um grupo ainda maior começou a correr atrás dela. Era o "pega-menina". A menina só ficava dizendo: "Pára, pára". Perguntei a um menino o que eles estavam fazendo. "Só estamos brincando", disse. Assim, vemos que a fala das meninas de que os meninos da sala são "fogo" vem reforçar um sistema de comportamentos condizentes e esperados para a condição de meninos.

Um outro jogo observado foi o jogo do esconde-esconde. Embora algumas crianças brincassem desse jogo algumas vezes no horário do parque, esse também era desenvolvido de outra forma: quando elas se escondiam de suas professoras. Era comum visualizar crianças que não estavam no horário do parque (o que indicava que deveriam estar com sua turma num outro espaço da escola) brincando com as outras turmas. Não era raro ver professoras saindo das salas e chamando por suas crianças "fugitivas". Percebemos também que a fuga da sala ocorria mais por parte dos meninos do que das meninas, fazendo com que as professoras procurassem (e se preocupassem) muito mais com a saída dos meninos.

Certo dia, um grupo de meninos fugitivos no parque se escondeu da professora que apareceu na porta da sala. Logo que ela entrou na sala, os meninos voltaram, fingiram que nada havia

Movimento, Porto Alegre, v.13, n. 01, p.13-37, janeiro/abril de 2007. 
acontecido e saíram novamente. Ficaram por um bom tempo nesse jogo de esconde-esconde com a professora. Num outro momento, alguns garotos brincavam de se esconder de sua professora enquanto sua turma se dirigia pelo trajeto do refeitório até a sala. Eles se escondiam, esperavam a turma passar e entravam no final da fila. Executavam isso com muita vivacidade, concentração e até com um certo medo de serem encontrados. Pediam uns aos outros que ficassem em silêncio, abaixados, de forma a não serem vistos.

Durante as brincadeiras de casinha, os rituais de maquiagem, as andanças pelo parque e as passagens pelos brinquedos, as meninas também articulavam os dispositivos de afirmação de pertencimento a um determinado grupo com determinadas regras, modos de agir, de se comportar. O grupo das meninas, por exemplo, era o único que andava de mãos dadas pelo parque, trazendo acessórios como colares, pulseiras, bolsas e maquiagem, além dos complementos necessários para a brincadeira da casinha. Vemos que a construção da identidade do grupo inscreve, nos corpos de cada criança, marcas que os diferenciam de outros grupos, tanto na relação entre grupos de salas diferentes ou mesmo pertencentes à própria sala.

\section{ANÁLISE E DISCUSSÃO}

Inicialmente, é importante salientar como o jogo/brincadeira promove a criação de grupos sociais diferenciados, que exprimem suas diferenças pelo e através do jogo nas mais diferentes atividades. Dessa forma, meninos e meninas são testados constantemente pelos próprios grupos na definição do lado em que estão nesse jogo do "gênero", através de mecanismos criados pelos próprios grupos.

Quando vimos, por exemplo, a execução dos gestos de balé por parte dos meninos, verificamos claramente que, ao executarem os movimentos daquela forma, tais gestos não eram pertencentes àquele determinado grupo e, sendo pertencentes ao "outro", são realizados de forma cômica, "desengonçada", pejorativa. O mesmo foi verificado pelos gestos da "lutinha" realizados pelas meninas e na cena do menino que não quis dançar no palco com as meninas,

Movimento, Porto Alegre, v.13, n. 01, p.13-37, janeiro/abril de 2007 
ou mesmo quando as meninas dificultaram a presença dos meninos na casinha e os meninos dificultaram a presença das meninas no futebol. Vimos, portanto, uma das formas pela qual os grupos "jogam" com essas regras de pertencimento. Um outro exemplo interessante desse "jogo", aliado aos mecanismos de pertencimento a um grupo, foi visualizado na "simulação" da briga do jogo de futebol dos meninos. A luta, no caso, constitui-se na representação de um jogo a partir do qual a masculinidade dos membros daquele determinado grupo mostra isso a todos (e a eles mesmos), o modo como eram, como agiam, de como se obtinha acesso àquele grupo restrito, que caracterizava o grupo dos meninos.

A partir da observação da relação palco (dança) X "pátio" (futebol), foi possível verificar um processo de delimitação dos espaços destinados aos meninos e às meninas, um "jogo" de poder que segue determinadas regras e que, aparentemente simples, apresenta-se de forma complexa. As próprias atividades desenvolvidas naquele espaço significavam e demarcavam espaços específicos destinados a meninos e meninas, no qual dificilmente ocorria ruptura e que delimitavam movimentos específicos para os diferentes grupos. Isso não impedia que os meninos passassem para o palco e que as meninas brincassem no "pátio". O lugar do palco era compreendido como local de pertencimento ao feminino, visto que grande parte das atividades ali desenvolvidas era considerada como sendo de 'meninas'.

Porém, não pretendemos nos prender à análise do eixo dicotômico do masculino-feminino, mas sim na forma pela qual essas categorias se intercruzam, relacionam-se e "jogam" com seus papéis para além dos estereótipos pré-definidos. Esse determinado grupo de crianças não recebe influência unívoca e passiva da sociedade. Para além disso, pelos jogos e brincadeiras, reconstroem e dinamizam essa relação, sendo também agentes nesse processo de construção dessa categoria de análise.

O que verificamos foram os mecanismos criados por ambos os grupos para se admitir ou não a presença do "outro", do "diferente", na brincadeira. Isso esteve presente tanto numa nova configu-

Mavimento, Porto Alegre, v.13, n. 01, p.13-37, janeiro/abril de 2007. 
ração da brincadeira quanto em um conjunto de códigos e regras diferentes que demonstrava a quem pertencia determinada atividade. Assim, o que fazia com que as meninas desistissem do futebol e os meninos desistissem da casinha? Eram os mecanismos criados pelos próprios grupos para dificultar o acesso à brincadeira. Brincadeira essa que pertencia a uma esfera de significados característicos de um determinado grupo. E o acesso a essa esfera de significados passava por determinados procedimentos criados pelo próprio grupo.

Esses mecanismos foram visualizados através dos empurrões, xingamentos, da nova configuração do jogo de futebol dos meninos, pelo fato das meninas falarem num tom mais ríspido com os meninos, virarem-se de costas e ficarem mais próximas dos acessórios na brincadeira da casinha. Foi possível verificar, dessa forma, que as próprias crianças se privavam das possibilidades de vivência de uma ou outra brincadeira pelas dificuldades criadas por esse determinado grupo, ou seja, os próprios sujeitos limitavam suas possibilidades de vivência das atividades. ${ }^{8}$

O futebol, nesse caso, configurava-se para os meninos como uma atividade restrita, na qual os mesmos faziam questão de mostrar isso a cada lance, a cada jogada. Assim, não era "natural" que os meninos brincassem de "lutinha" e as meninas brincassem de casinha. Esse determinado grupo de crianças "jogava" com diferentes níveis de atividades e desenvolviam, por um lento e gradativo processo de construção cultural, os significados que orientavam as ações e comportamentos daquele determinado grupo.

Isso foi verificado na forte verbalização realizada pelos meninos no jogo de futebol, expressada pelos xingamentos, gritos, que muitas vezes desembocavam numa violência real. O "carrinho" no jogo de futebol foi interpretado como um ato de violência permitida, legitimado pelo fato de estar inserido no jogo de futebol, fato que é "natural" dessa prática esportiva. Vimos também que a presença

${ }^{3}$ Ao analisar as obras que caracterizam a chamada Sociologia da Infância na França, Sirota (2001, p.28) verificou que grande parte dos trabalhos analisados procura "[...] compreender aquilo que a criança faz de si e aquilo que se faz dela, e não simplesmente aquilo que as instituições inventam para ela".

Movimento, Porto Alegre, v.13, n. 01, p.13-37, janeiro/abril de 2007. 
de meninas neste jogo tornava o ambiente mais hostil. ${ }^{9}$ Isso, porém, não era algo restrito ao grupo dos meninos. Os grupos das meninas também se utilizavam dessa violência simbólica, principalmente no jogo da casinha. Nesse sentido, a presença dos meninos nesta atividade fazia com que elas mudassem o tom de voz e alterassem o seu comportamento corriqueiro.

O grupo, dessa forma, agia como um sistema regulador, ao fornecer a lógica de significados que iriam direcionar as ações e os próprios comportamentos do grupo e dos indivíduos. As diferentes brincadeiras realizadas pelo parque tais como a "lutinha", as rodinhas de maquiagem, a "casinha", o futebol, solicitavam atitudes e comportamentos esperados que caracterizariam os diferentes grupos.

Foi possível também estendermos essa análise para a relação estabelecida entre criança-adulto nessa instituição educacional específica. Essa relação não se configurava pura e simplesmente numa relação hierárquica na qual crianças se submetiam a um rígido controle disciplinar ao qual deviam plena obediência às suas professoras. As crianças criam formas alternativas de quebrar a "ordem" colocada pela instituição em questão, representada principalmente pela autoridade da professora. Isso foi verificado no exemplo do jogo do esconde-esconde.

Vimos como esse jogo proporcionava uma outra ordem na relação criança/adulto quando era realizado com a professora, pois o mesmo agia como uma quebra da rigidez e da formalidade escolar. Interessante verificarmos como as crianças tentavam resolver os casos mais conflituosos com a professora, nos quais a mesma atuava como uma espécie de "juíza". Essa, por muitas vezes, não rompia com as concepções pré-estabelecidas (e por vezes até reforçava) das diferenças de gênero nos jogos/brincadeiras realizados pelas crianças.

As crianças, dessa forma, não se submetiam diretamente às regras do ambiente educacional, mas "jogavam" com ela, experimentavam até onde era possível ganhar e ceder nessa relação, não

${ }^{9}$ Hostilidade expressa através dos gritos, xingamentos e a partir da nova configuração do jogo, embora não chegasse a violência física.

Movimento, Porto Alegre, v.13, n. 01, p.13-37, janeiro/abril de 2007. 
se configurando numa relação de disciplina/obediência por parte das crianças, nem tão somente de resistência delas frente à organização escolar, mas sim no "jogo" travado entre esses dois extremos. Para Tedrus (1998, p.50), “[...] a relação criança/adulto é muito dinâmica e recoloca em permanente conflito este jogo de posições de poder cujos personagens conjuntamente definem e redefinem regras e mais regras de viver em comum".

\section{CONSIDERAÇÕES FINAIS}

Procuramos desenvolver ao longo dessa pesquisa um processo de "desconstrução" e desmistificação dos estereótipos traçados para a infância e, dentro dessa categoria, os estereótipos traçados para os gêneros. Como vimos, e nos é reforçado por Scott (1990), a questão do gênero implica um conjunto de símbolos culturalmente disponíveis na sociedade. Segundo a autora, as interpretações dos significados desses símbolos presentes nas mais diferentes instituições, sejam elas religiosas, científicas ou educacionais, são aquelas responsáveis por construírem o significado de homem e de mulher, de masculino e de feminino (SCOTT, 1990, p.86). Ou seja, para além de generalizações ou concepções absolutas, a forma centrada no significado é de fundamental importância para uma análise que fuja das concepções binárias e que leve em consideração a especificidade de cada grupo social, podendo, dessa forma, desconstruir os estreótipos traçados para os sexos. ${ }^{10}$

A partir dessas considerações, as crianças, como sujeitos da pesquisa, configuram-se como um grupo com características próprias, que não se apresentam somente como simples reprodutoras das técnicas do mundo adulto, mas sim como um grupo que ressignifica determinadas técnicas corporais de seu meio social e as articula em seu cotidiano. A análise etnográfica, assim como o referencial fornecido pela Antropologia Social, configurou-se num

${ }^{10}$ Joan Scott (1990, p.22) afirma que os principais estudos sobre gênero enfatizam "[...] a necessidade de uma rejeição do caráter fixo e permanente da oposição binária [masculino versus feminino], de uma historicização e desconstrução genuínas dos termos da diferença sexual [...] em vez de aceitá-la como real ou auto-evidente ou como fazendo parte da natureza das coisas".

Movimento, Porto Alegre, v.13, n. 01, p.13-37, janeiro/abril de 2007. 
importante instrumento de análise na busca por essa 'teia' de significados. Isso, em grande, parte só foi possível nessa pesquisa pela utilização de uma abordagem metodológica que, procurando interpretar um texto observado num determinado contexto, foi em busca dos significados de determinadas ações para determinados sujeitos que, no caso, crianças, muitas vezes não são entendidas em suas próprias manifestações, mas como reprodutoras do mundo adulto. Em decorrência dos limites de um artigo, é, por vezes, difícil abranger a ampla gama de significados que envolvem as brincadeiras de um determinado grupo de crianças no ambiente préescolar. Porém, fica o estímulo à comunidade acadêmica pela busca de uma análise mais minuciosa quando se depara com o universo da criança e de suas representações que, por vezes, diferem muito daquelas construídas pelo adulto.

\footnotetext{
Ethnographical analysis of gender relations in pre-school children's games: contributions of a research searching for meanings

Abstract: This research was founded in the knowledge provided by the Human Sciences, especially, the Social Anthropology, in order to analyze how a determined group of pre-scholars confer meaning to the gender relations in games performed in a school environment. In this article, the methodological procedures are emphasized since they are necessary to interpret the "relationship plots" created by the categories considered, such as childhood, gender and school system. Moreover, the qualitative research has become more frequent in the Physical Education field, enlarging the understanding of the significance present in human relations.

Keywords: Anthropology, cultural. Gender identity. Child, preschool.
}

Movimento, Porto Alegre, v.13, n. 01, p.13-37, janeiro/abril de 2007. 


Análisis etnográfica de las relaciones de género
en bromas realizadas por un grupo de niños de
la pre-escuela: contribuciones para una investi-
gación en búsqueda de los significados
Resumen: Esta investigación partió del referencial
suministrado por las Ciencias Humanas, en espe-
cial lo de la Antropología Social, para analizar como
un determinado grupo de niños de pre-escuela
confiere significados a las relaciones de género en
las bromas por ellas realizadas en el ambiente de
una guardería. En este trabajo, fue enfatizado el
procedimiento teórico-metodológico utilizado para
la realización de la investigación, por posibilitar la
interpretación de la trama compuesto por las cate-
gorías de infancia, género e institución escolar.
Además de eso, la investigación cualitativa he se
hecho frecuente en el área de Educación Física,
ampliando la comprensión de los significados pre-
sentes en las acciones humanas.
Palabras clave: Antropología cultural. Identidad de
género. Preescolar.

\section{REFERÊNCIAS}

ANDRÉ, M. E. D. A. Etnografia da prática escolar. Campinas: Papirus, 1995.

AZZAN JÚNIOR, Carlos. Antropologia e interpretação: explicação e compreensão nas antropologias de Lévi-Strauss e Geertz. Campinas: Ed. Unicamp, 1993.

CHAUÍ, Marilena. Convite à filosofia. São Paulo: Ática, 1994.

DELAMONT, Sara. Os papéis sexuais e a escola. Lisboa: Livros Horizonte, 1985

GEERTZ, Clifford. A interpretação das culturas. Rio de Janeiro: Guanabara 1989.

KUPER, Adam. Cultura: a visão dos antropólogos. Bauru: EDUSC, 2002.

LAPLANTINE, François. Aprender antropologia. São Paulo: Brasiliense, 1988.

LOURO, Guacira Lopes. Educação e gênero: a escola e a produção do feminino e do masculino. In: SILVA, L. H.; AZEVEDO, J. C. (Org.) Reestruturação curricular: teoria e prática no cotidiano da escola. Petrópolis: Vozes, 1995.

LOURO, Guacira Lopes. (Org.) O corpo educado: pedagogias da sexualidade. Belo Horizonte: Autêntica, 1999.

LUZ JÚNIOR, Agripino. Educação física e gênero: olhares em cena. São Luís: Imprensa Universitária/UFMA/CORSUP, 2003.

Movimento, Porto Alegre, v.13, n. 01, p.13-37, janeiro/abril de 2007. 
MALINOWSKI, Bronislaw. Os argonautas do Pacífico Ocidental: um relato do empreendimento e da aventura dos nativos nos arquipélagos da Nova Guiné Melanésia. São Paulo: Abril, 1984

MARQUES DA SILVA, Alan. Infância, Jogo e Gênero: uma etnografia do brincar. Campinas, Universidade Estadual de Campinas, Faculdade de Educação Física, 2003. Trabalho de Conclusão de Curso.

MOLINA NETO, Vicente; TRIVIÑOS, Augusto Nibaldo Silva (Org.). A pesquisa qualitativa na educação física: alternativas metodológicas. Porto Alegre: Ed. Universidade/UFGRS/Sulina, 1999.

OLIVEIRA, Nara Rejane Cruz. Concepção de infância na educação física brasileira: primeiras aproximações. Revista Brasileira de Ciências do Esporte, São Paulo, v. 26, n. 3, p.95-109, maio 2005.

OLIVEIRA, Roberto Cardoso. Sobre o pensamento antropológico. Rio de Janeiro: Tempo Brasileiro, 1997.

SCOTT, J. Gênero: uma categoria útil de análise histórica. Educação e Realidade, Porto Alegre, v. 15, n. 2, jul./dez. 1990.

SIROTA, Regine. Emergência de uma sociologia da infância: evolução do objeto e do olhar. Cadernos de Pesquisa, Florianópolis, n. 112, p.7-31, mar. 2001.

TEDRUS, Dora Maria Almeida Sousa. A relação adulto-criança: um estudo antropológico em creches e escolinhas de Campinas. Campinas: Unicamp, 1998.

Movimento, Porto Alegre, v.13, n. 01, p.13-37, janeiro/abril de 2007. 